\title{
Motivational Beliefs and Self-Regulation in Biology Learning: Influence of Ethnicity, Gender and Grade Level in Kenya
}

\author{
Richard Owino Ongowo ${ }^{1 *}$, Samuel Kahungu Hungi² \\ ${ }^{1}$ Department of Educational Communication Technology and Curriculum Studies, Maseno University, Maseno, \\ Kenya \\ ${ }^{2}$ Department of Curriculum and Instruction, Egerton University, Njoro, Kenya \\ Email: r owino@yahoo.com, sam.hungi@yahoo.com
}

Received 8 January 2014; revised 8 February 2014; accepted 15 February 2014

Copyright (C) 2014 by authors and Scientific Research Publishing Inc.

This work is licensed under the Creative Commons Attribution International License (CC BY). http://creativecommons.org/licenses/by/4.0/

(c) (i) Open Access

\begin{abstract}
The study investigated the influence of ethnicity, gender and grade level on the motivational beliefs and self-regulation in Biology learning through a non-experimental quantitative study among 317 students in 2 co-educational schools in Nakuru $(n=155)$ and Siaya $(n=162)$ counties, Kenya. The study used a modified version of Motivated Strategies for Learning Questionnaire (MSLQ) which had 44 items to measure motivational beliefs and self-regulation. A $4 \times 2 \times 2$ MANOVA revealed "ethnicity" as having the largest effect on these variables. There was a statistically significant difference between the Nakuru group and the Siaya group in favor of Nakuru with regard to self-efficacy in Biology learning. They also scored higher in most of the variables. There were no statistically significant gender differences in motivational beliefs and self-regulation in Biology learning. However boys were more self-efficacious with low test anxiety than girls. Girls had higher intrinsic value, cognitive strategy and self-regulation than boys. There were statistically significant grade level differences in favor of grade 12 students. Grade 11 students had the lowest scores in all the variables under investigation. The implications for the study are discussed.
\end{abstract}

\section{Keywords}

Motivational Beliefs; Self-Regulation; Biology Learning; Coeducational Schools

\section{Introduction}

The contemporary thinking in science education is that individuals should assume personal responsibility and "Corresponding author.

How to cite this paper: Ongowo, R. O., \& Hungi, S. K. (2014). Motivational Beliefs and Self-Regulation in Biology Learning: Influence of Ethnicity, Gender and Grade Level in Kenya. Creative Education, 5, 218-227. 
control for their own acquisition of knowledge and skills. In this regard students should become masters of their own learning. This pedagogical shift has led to a change in the role of the teacher from a transmitter of knowledge to that of a facilitator, guide and motivation optimizer in the learning environment (Zimmerman, 1990; Palmer, 2005; Cavas, 2011). A number of studies have been directed towards the affective components of cognition. Within the affective components, motivation and self-regulation are becoming important because of the crucial role that they play in the process of cognitive engagement and conceptual change (Pintrich, Marx, \& Boyle, 1993; Tuan, Chin, \& Shieh, 2005; Tang \& Neber, 2008).

\section{Literature Review}

Motivation has been defined as an internal state that activates, guides, and maintains behavior (Green, 2002). Motivation to learn science is therefore the engagement in science related tasks with the goal of achieving a better understanding of science and the activation of strategies for doing so (Lee \& Brophy, 1996). Motivation to learn is of particular interest in science education because of the relationship between motivation, cognitive engagement and conceptual change (Pintrich, Marx, \& Boyle, 1993). Nelson and Debacker (2000) posit that conceptual change is a difficult task due to the requirement that new information be engaged at a sufficiently deep level to recognize conflicts between existing understanding and new information. Evidence suggests that decisions to engage in effortful learning may be affected by individual students' motivation including their goals for engaging in an activity, their beliefs about their abilities and the nature of the task, and their valuing of the task (Nolen \& Haladyna, 1990; Greene \& Miller, 1996). In the view of Cavas (2011), motivation to learn science promotes student construction of their conceptual understanding of science. It is a variable that promotes both new learning and performance of previously learnt skills, strategies and behaviors. Lee and Brophy (1996) opine that students who are motivated to learn science display a high quality of task engagement in science classrooms. In terms of behavioral engagement, they pay attention to lessons and are actively involved in class- room activities. These students also activate cognitive and meta-cognitive strategies to the goal of understanding science in specific task situations. Mills (1991) holds that the teaching strategy that a teacher adopts is a strong factor that affects students' motivation towards learning. This would therefore mean that cognitive engagement in science requires individual student motivation, including their determination to take charge of the learning process. This is likely to translate into high achievement in science.

\subsection{Motivational Beliefs}

Recent research in motivation has shifted from the behaviorist perspective to social cognitive perspective that emphasizes the importance of students' beliefs about themselves, strategies and their learning environment. This view also holds that motivation and learning strategies are dynamic, multifaceted phenomena that are more situated, contextual and domain specific (Palmer, 2005; Jahedi, 2007; Dancun \& Mc Keachie, 2005). Motivational beliefs refer to the opinions, judgments and values that students hold about objects, events or subject matter domains. Motivational beliefs act as a frame of reference that guide students thinking, feelings and actions in a subject area (Boekaerts, 2002). Although there are a variety of constructs that have been proposed that have the potential to inform motivation in school settings the study was limited to three motivational beliefs. In this study the motivational beliefs that were focused on are self-efficacy beliefs, intrinsic value beliefs and test anxiety.

Self-efficacy has been defined as a belief in ones' ability to perform effectively. It is concerned with an individual's belief that they can organize and execute courses of action required to deal with prospective situations that contain many ambiguous, unpredictable and often stressful elements (Bandura, 1982). Tang and Neber (2008), posit that self-efficacy represents the learners' subjective belief in their own competence for high domain specific achievements. In other words, self-efficacy is a self-assessment belief concerning ones' ability to master a task whether easy or difficult to produce positive outcomes. It includes the learners' judgments about their ability to complete a task and confidence in their skills to conduct the task at hand. Bandura (cited in Palmer, 2005), described four factors that can improve self-efficacy as mastery experiences, vicarious experiences, verbal persuasions and the affective state. Recent research has shown that self-efficacy beliefs significantly influence academic achievement and they specifically constitute the most powerful indicator of the performance in Mathematics tasks (Gaskill \& Murphy, 2004).

Intrinsic value is the measure of one's personal enjoyment or satisfaction from engaging in tasks within the learning domain (Nelson \& Debacker, 2000). In the view of Palmer (2005) this is the value component of moti- 
vational belief and refers to inherent enjoyment in a task and very closely related to the constructs of intrinsic motivation and interest. Intrinsic value includes students' goals for the task and their beliefs about importance of interest in and value in the task. According to Green (2002), children's value beliefs about particular subjects are positively correlated with the amount of previous success they have experienced in those subjects. In this regard, Green suggests that intrinsic value of tasks should be promoted whenever a teacher provides a reason for the task, emphasizes the usefulness and importance of the task, and emphasizes the enjoyment that can be gained from the task.

According to Basco \& Olea (2013), anxiety is an unpleasant emotion characterized by worry, apprehension, dread and fear in varying degree. Test anxiety is a subjective emotional state experienced before or during a specific evaluation relating to the act of completing the evaluation itself, the threat of failing, and the perceived negative consequences (Karatas, Alci, \& Aydin, 2013). According to Ozkan (2003), test anxiety is the affective component of motivational beliefs which includes students' emotional reactions to tasks and taps into students worry and concern over taking exams. Basco \& Olea (2013), hold that test anxiety is a major factor contributing to a variety of negative outcomes including psychological distress, academic underachievement, academic failure and insecurity. A study carried out by Jahedi (2007) found out that test anxiety as a motivational belief had a negative correlation to self-efficacy, intrinsic value, cognitive strategy and self-regulation. This implied that students who had high test anxiety were less confident, less motivated to learn and less likely to use cognitive and meta-cognitive strategies. Karatas, Alci and Aydin (2013), found out a significant reverse correlation between students' test anxiety and points of university entrance exam. On the other hand gender analysis showed that there was a significant reverse correlation between female students' test anxiety and points of university entry exam

\subsection{Self-Regulated Learning}

Self-regulated learning has been conceptualized differently by different scholars. Pintrich (cited in Tang \& Neber, 2008), hold that it is an active, constructive process whereby learners set goals for their learning and then attempt to monitor, regulate and control their cognition, motivation and behavior, guided and constrained by their goals and the contextual features in the environment. On the other hand Zimmerman (cited in Eccles \& Wigfield, 2002), emphasize that the construct has various dimensions as cognitive, meta-cognitive, motivational, behavioral and environmental processes. According to Molnar (cited in Mezei, 2008), the teachers perceive self-regulated learning as one consisting of student initiated learning, student autonomy and use of efficient learning strategies, student reflection on their work, and intrinsic goal setting. Schoenfeld (cited in Marcou \& Philippou, 2005), opines that self-regulation is the learners' ability to use both meta-cognitive and cognitive learning strategies. Zimmerman (1990) suggests that self-regulated learning is a self-oriented feedback loop that entails a cyclic process in which students monitor the effectiveness of their learning methods or strategies and react to this feedback in a variety of ways ranging from covert changes in self-perception to overt changes in behavior such altering the use of learning strategy. Underlying these conceptions is the fact that self-regulated learning actively involves the learner cognitively; the learner meta-cognitively controls the learning process, the learner develops multiple approaches to learning in the face of challenges. In the face of all these activities on the part of the learners, they must have certain motivational orientations. These conceptions also emphasize the relationship between motivational beliefs and self-regulation.

Research in self-regulated learning has been done in different domains. Mezei (2008) found out that self-regulated learning capacity is a function of proficiency and or individual difference factors. Mezei also added that higher-level learners are more conscious about the processes of their learning and also of how to regulate their learning behavior. Mih \& Mih (2010) found that advanced meta-cognition is linked with high self-efficacy and good learning achievements. They further held that Competency goals are good predictors of advanced processing. Competent pupils use self-regulatory learning strategies in comparison to less competent students. Yucel (2013) carried out a study to find out the effect of blog use on self-regulatory learning of prospective German language teachers and concluded that the learning process supported by blog use applications positively influenced various self-regulated learning dimensions of prospective teachers. Tang and Neber (2008) carried out a survey regarding the motivation and self-regulation in Chemistry learning among Americans, Chinese and Germans. The findings indicated that the American group scored higher than their Chinese and German counterparts in motivational and self-regulatory characteristics. 
Researchers in science education have observed that the construction of scientific knowledge takes place in a cultural environment. Ausubel, Novak and Hensian (cited in Keraro, Okere, \& Anditi, 2013) have suggested that the construction of new knowledge in science is strongly influenced by prior knowledge, that is conceptions gained prior to formal learning. These prior constructions take place in a cultural context created by socio-economic class, religion, geographical location, ethnicity and language. Jahedi (2007) observes that the motivation of learners is more situated, contextual and domain specific. Boekaerts (2002), notes that the content of science covered in the classroom and the social context vary continuously and creates ambiguity and uncertainty for other students. Linnenbrink and Pintrich (2002) add that an individual's personality, demography and culture influence the motivation of the learners. Meece, Glienke and Burg (2006) in a seminal review of gender and motivation regretted a deficiency of research examining gender differences in motivation within ethnic, racial and socio-economic contexts. Pintrich and Zusho (cited in Tang \& Neber, 2008) noted a lack of cross-cultural and cross-national studies on self-regulated learning. Meece, Glienke and Burg continue to emphasize the existence of heterogeneity in terms of culture, race and socio-economic status that would shape students' learning experiences within the school environment. Keraro, Okere and Anditi (2013) observe that African children are engrossed and indulged in a cultural environment characterized by beliefs, myths and practices that shape their perception and cognition of scientific phenomena. Kenya is a multi-ethnic society with different beliefs which are likely to impact on the process of biology learning and this is likely to engender different motivational beliefs and self-regulation strategies.

\section{Problem and Purpose of the Study}

Most of the studies in biology education have been focused on the student cognition aspects. Despite the robust findings from such studies that could lead to better results, the performance in biology in the Kenya national examination council remains poor. A number of factors have been attributed to this sorry state like inappropriate teaching methodology, content difficulty from the learners' perspective, lack of teaching resources. However affective and cultural factors have been known to be determinants of the process of cognition. Of the affective factors, motivation and self-regulation are known to play more superior roles as far as cognitive engagement and achievement are concerned. The current study sought to establish the relationship between motivational beliefs and self-regulation in Biology learning and the differences related to ethnicity, gender and grade level in Nakuru and Siaya Counties dominated by Kikuyu and Luo ethnic communities respectively in Kenya.

\subsection{Research Questions}

The study was guided by the following questions:

- Are there ethnic differences in motivational beliefs and self-regulation in biology learning among the Kikuyu and Luo students in coeducational schools?

- Are there gender differences in motivational beliefs and self-regulation in biology learning among the Kikuyu and Luo students in coeducational schools?

- Are there grade-level differences in motivational beliefs and self-regulation in biology learning among the Kikuyu and Luo students in coeducational schools?

\subsection{Theoretical Framework}

The current study will be built on the Social Cognitive Theory by Bandura (Bandura, 2001). According to this theory, students' motivation is directly linked to their ability to self-regulate their learning activities.Generally; self-regulated learning describes how learners meta-cognitively, motivationally and behaviorally improve their own academic achievement. Meta-cognitively, self-regulated learners plan, organize, self-evaluate and selfmonitor at various stages of the learning process. Motivationally, they perceive themselves as competent, selfefficacious, autonomous and value their academic pursuits. Behaviorally, they select structure and sometimes even create environments that optimize learning (Zimmermann, 1989). The social cognitive framework assumes that motivation and learning strategies are not static traits of the learner but that motivation is a dynamic and contextually bound construct. At the same time learning strategies can be learned and brought under control by the student (Duncan \& McKeachie, 2005). In this study motivational beliefs and self-regulatory strategies of students were determined in the domain of biology using Motivated Strategies for Learning Questionnaire 
(MSLQ).

\section{Methodology}

\subsection{Research Design and Sample}

This research was a non-experimental quantitative research. A non-experimental research does not involve manipulation of variables because their manifestations have occurred or because they have fixed manipulative and uninfluenceable properties (Mugenda \& Mugenda, 2003). The researchers therefore examined the influence of grade level, gender and ethnicity/culture (independent variables) on motivational beliefs and self-regulation (dependent variables). In this study, quantitative data were gathered from 317 students in 2 coeducational schools (one from Siaya County and one Nakuru County). The two schools were purposively selected since they had the characteristics required for the study. Purposive sampling is appropriate where characteristics of the population are known or information rich with regard to the purpose of the study (Gall, Borg, \& Gall, 2003). Nakuru is dominated by Kikuyu ethnic community whereas Siaya is predominantly composed of Luo ethnic community. Sampling was carefully done to ensure that only coeducational schools dominated by kikuyus and Luos were selected for the study. Table 1 shows the sample characteristics.

\subsection{Instrumentation}

A modified version of Motivated Strategies for Learning Questionnaire (MSLQ) by Pintrich and DeGroot (1990) was used to assess the students' motivational beliefs and self-regulation. The instrument had 44 items with 5 scales. Table 2 shows the scales and scale descriptions of the instruments. The entire instrument was modified to specifically measure motivational beliefs and self-regulation in Biology learning. The motivational beliefs were measured by the motivational subscale consisting of 22 items of the MSLQ. These items measured three motivational factors (self-efficacy, intrinsic value and test-anxiety) within the domain of biology. The items were answered on a seven-point likert scale $(1=$ not at all true of me; 7 = completely true of me). Self-regulated Biology learning strategies were measured by the self-regulated learning subscale consisting of 22 items of the MSLQ. These items measure two regulatory strategies including cognitive strategies and self-regulatory strategies. The cognitive strategies are concerned with processing information within the domain of biology and selfregulatory strategies are concerned with meta-cognitive control of biology learning activities. The instrument was piloted in a school not participating in the study and had an entire reliability of 0.81 . These items were also answered on a seven-point likert scale. The researchers collected data in July 2013 during the school sessions of students from Siaya and Nakuru Counties. The necessary clarifications were given to the students before they responded to the items of MSLQ.

\section{Results}

\subsection{Data Analyses}

The data collected were analyzed using the program Statistical Package for Social Sciences (SPSS) version 17.

Table 1. Sample characteristics by grade, gender and location.

\begin{tabular}{|c|c|c|c|c|}
\hline Grade & Gender & Nakuru & Siaya & Total \\
\hline \multirow{2}{*}{ Grade 9} & Girls & 27 & 25 & 52 \\
\hline & Boys & 16 & 29 & 44 \\
\hline \multirow{2}{*}{ Grade 10} & Girls & 24 & 10 & 34 \\
\hline & Boys & 20 & 30 & 50 \\
\hline \multirow{2}{*}{ Grade 11} & Girls & 7 & 27 & 34 \\
\hline & Boys & 19 & 16 & 35 \\
\hline \multirow{3}{*}{ Grade 12} & Girls & 18 & 22 & 40 \\
\hline & Boys & 7 & 20 & 27 \\
\hline & Total & 155 & 162 & 317 \\
\hline
\end{tabular}


Table 2. Scale and scale descriptions of MSLQ.

\begin{tabular}{ll}
\hline Scale & Scale Descriptions \\
\hline Self-efficacy & Extent to which students believe they can perform in biology tasks \\
Intrinsic Value & Level of importance attached to Biology learning \\
Test Anxiety & Students' emotional reactions to Biology examinations \\
Cognitive Strategy & Students' strategy for processing biological knowledge \\
Self-regulation Strategy & Strategy for self-control and self-management in Biology learning \\
\hline
\end{tabular}

MANOVA was performed to determine the multivariate effect of the predictor (independent) variables on the scores of the students for motivational beliefs and self-regulation (dependent variables). To check for robustness, a preliminary test was done using Box's M test for homogeneity of covariance matrices. The result was significant at $p<0.001$ implying that robustness was not guaranteed. This may have been related to unequal sample sizes of the two subgroups. According to Tabachnick and Fidell (2007), under such circumstances, Pillai’s Trace criterion becomes handy. The multivariate $\mathrm{F}$ values in this study were based on Pillai's Trace.

Differences among groups were assessed by applying a $4 \times 2 \times 2$ (Grade $\times$ Gender $\times$ Ethnicity) multivariate analysis of variance (MANOVA) with all motivational beliefs and self-regulation measures described above. Univariate tests were done after analysis of multivariate effects. All main effects for ethnicity, gender and grade were significant (significance level: $p<0.05$ ). The largest effect size was found for ethnicity $F(5,297)=4.688$, $p=0.00, \eta^{2}=0.073$. The main effects for gender, $F(5,297)=3.408, p=0.005, \eta^{2}=0.054$ and for grade level, $F(15,897)=2.870, p=0.00, \eta^{2}=0.046$ were less conspicuous. The only significant two-factorial interaction was found between grade level and ethnicity, $F(15,897)=1.825, p=0.027, \eta^{2}=0.030$.

\subsection{Ethnic Differences}

The multivariate effect of the factor ethnicity on motivational beliefs and self-regulation was relatively higher than the rest $\left(\eta^{2}=.073\right)$. Table 3 shows the results of univariate analysis on the variable ethnicity. The analysis shows that there was a statistically significant difference in self-efficacy in Biology learning in favor of the Nakuru sample. The Nakuru sample also had higher means in the variables- intrinsic value, test anxiety and cognitive strategy but not statistically significant. The Siaya sample had higher mean on self-regulation than the Nakuru sample though not significant. Concerning the interaction between ethnicity and grade-level significant $\mathrm{F}$ values were found for test anxiety $(F=5.894, p<0.05)$. Post-hoc tests showed that these interactions produced significant differences between grade 9 and grade 12 for the Nakuru and Siaya samples. There were no significant differences in the interaction between ethnicity and gender.

\subsection{Gender Differences}

For gender as a fixed factor, the multivariate test provided a significant effect size $\left(\eta^{2}=0.054\right)$. Possible genderrelated differences of the three motivational beliefs and two self-regulation strategies were tested using univariate analyses whose results are shown in Table 4. It can be seen that there were no statistically significant gender differences in any of the variables under the study. The boys manifested a higher self-efficacy than girls (Girls, $M=43.15, S D=8.558$; Boys, $M=44.18$, 8.618). At the same time, the boys had a lower test anxiety than girls (Girls, $M=28.04, S D=9.371$; Boys, $M=28.94$, $\mathrm{SD}=9.626$ ). However, the girls outperformed the boys in the rest of the variables under investigation as shown by the means in Intrinsic value (Girls, $M=47.46$, $S D=7.926$; Boys, $M=47.33, S D=7.230$ ), Cognitive strategy (Girls, $M=63.72, S D=8.678$; Boys, $M=62.22$, $S D=9.059$ ), and Self-regulation (Girls, $M=47.48, S D=8.482$; Boys, 45.80, $S D=9.926$ ).

\subsection{Grade-Related Differences}

The multivariate effect of the factor grade-level attained a significant level but remained comparatively low in terms of effect size $\left(\eta^{2}=0.046\right)$. The results of the univariate tests are presented in Table 5. As can be seen, two motivational beliefs variables (intrinsic variable and test anxiety) and one strategy variable (self-regulation) 
Table 3. Ethnic differences in motivational beliefs and strategy variables.

\begin{tabular}{ccccccccc}
\hline \multirow{2}{*}{ Variables Motivational beliefs } & \multicolumn{9}{c}{ Siaya } & \multicolumn{1}{c}{ Nakuru } & & \\
\cline { 2 - 8 } & $\boldsymbol{M}$ & $\boldsymbol{S D}$ & $\boldsymbol{M}$ & $\boldsymbol{S D}$ & $\boldsymbol{F ( 1 , 3 1 5 )}$ & $\boldsymbol{p}$ & eta $^{2}$ \\
\hline Self-efficacy & 41.12 & 9.14 & 45.27 & 7.689 & 11.003 & $0.001^{*}$ & 0.034 \\
Intrinsic value & 47.24 & 7.323 & 48.55 & 7.855 & 0.136 & 0.505 & 0.000 \\
Test anxiety & 28.46 & 9.395 & 29.52 & 9.626 & 0.424 & 0.516 & 0.000 \\
Strategy variables & & & & & & & \\
Cognitive strategy & 62.59 & 9.375 & 63.39 & 8.357 & 1.441 & 0.231 & 0.002 \\
Self-regulation & 47.15 & 9.625 & 45.12 & 8.840 & 0.295 & 0.587 & 0.003 \\
\hline
\end{tabular}

Note: $p<0.05$.

Table 4. Gender differences in motivational beliefs and strategy variables.

\begin{tabular}{|c|c|c|c|c|c|c|c|}
\hline \multirow{2}{*}{ Variables Motivational beliefs } & \multicolumn{2}{|c|}{ Girls } & \multicolumn{2}{|c|}{ Boys } & \multirow[b]{2}{*}{$F(1,315)$} & \multirow[b]{2}{*}{$p$} & \multirow[b]{2}{*}{ eta $^{2}$} \\
\hline & $M$ & $S D$ & $M$ & $S D$ & & & \\
\hline Self-efficacy & 43.15 & 8.558 & 44.18 & 8.618 & 1.135 & 0.288 & 0.004 \\
\hline Intrinsic Value & 47.46 & 7.926 & 47.33 & 7.230 & 0.022 & 0.883 & 0.000 \\
\hline Test anxiety & 28.04 & 9.371 & 28.94 & 9.626 & 0.720 & 0.397 & 0.002 \\
\hline \multicolumn{8}{|l|}{ Strategy Variables } \\
\hline Cognitive strategy & 63.72 & 8.678 & 62.22 & 9.059 & 2.273 & 0.133 & 0.007 \\
\hline Self-Regulation & 47.48 & 8.482 & 45.80 & 9.926 & 2.644 & 0.105 & 0.008 \\
\hline
\end{tabular}

Note: $p<0.05$.

Table 5. Grade level differences in motivational beliefs and strategy variables.

\begin{tabular}{|c|c|c|c|c|c|c|c|c|c|c|c|}
\hline \multirow{2}{*}{ Variables MB } & \multicolumn{2}{|c|}{ Grade 9} & \multicolumn{2}{|c|}{ Grade 10} & \multicolumn{2}{|c|}{ Grade 11} & \multicolumn{2}{|c|}{ Grade 12} & \multirow[b]{2}{*}{$F(3,313)$} & \multirow[b]{2}{*}{$p$} & \multirow[b]{2}{*}{ eta $^{2}$} \\
\hline & $M$ & $S D$ & $M$ & $S D$ & $M$ & $S D$ & $M$ & $S D$ & & & \\
\hline SE & 43.85 & 8.061 & 43.36 & 8.826 & 43.46 & 9.221 & 45.21 & 8.300 & 1.399 & 0.243 & 0.013 \\
\hline IV & 46.70 & 7.095 & 48.49 & 6.762 & 44.81 & 9.644 & 49.69 & 5.816 & 5.816 & $0.001^{*}$ & 0.053 \\
\hline $\mathbf{T A}$ & 29.74 & 9.014 & 28.18 & 10.053 & 25.16 & 9.982 & 30.48 & 8.097 & 4.551 & $0.004^{*}$ & 0.042 \\
\hline \multicolumn{12}{|l|}{ SV } \\
\hline CS & 63.19 & 8.201 & 62.23 & 8.499 & 61.64 & 11.408 & 65.01 & 9.646 & 1.931 & 0.124 & 0.018 \\
\hline SR & 44.81 & 8.537 & 47.93 & 8.481 & 45.39 & 9.399 & 46.65 & 9.249 & 3.753 & $0.011^{*}$ & 0.035 \\
\hline
\end{tabular}

Note: MB = Motivational beliefs, SE = Self-Efficacy, IV = Intrinsic Value, TA = Test Anxiety, SV = Strategy Variables, CS = Cognitive Strategy, SR $=$ Self-Regulation, ${ }^{*} p<0.05$.

showed statistical significance among the various grade levels. Post-hoc analyses using Tukey revealed that with regard to intrinsic value, there were significant differences between grade 10 and 11 in favor of grade 10 and between grade 11 and grade 12 in favor of grade 12 . With regard to test anxiety, there were significant differences between grade 9 and 11 in favor of grade 9 and between grade 11 and grade 12 in favor of grade 12 . With regard to self-regulation, there were significant differences between grade 9 and 12 in favor of grade 12 .

Concerning the interactions between grade-level and gender, significant $F$ values were found for self-regulation $(F=3.561, p<0.05)$. Post-hoc tests revealed that these interactions produced significant differences between grade 9 and 12 for the boy and girl samples. The grade 9 boys and girls attained lower means than the 
grade 12 boys and girls.

\section{Discussion}

From the data analysis, the factor "ethnicity" resulted in more pronounced effect on motivational beliefs and self-regulation strategies than the factors of "gender" and "grade level". Significant ethnic differences were in favor of the Nakuru sample on the domain of self-efficacy. The mean performance of students on the domains of intrinsic value, test anxiety and cognitive strategy was also higher than that of the Siaya students though not statistically significant. On the other hand, the Siaya students seemed to apply self-regulatory strategies than their counterparts in Nakuru though not to a significant level. These findings are more or less the same as those found by Tang and Neber (2008). They found out that students from three different cultures (American, German and Chinese) performed significantly different on motivational and self-regulatory characteristics in Chemistry. It would appear that the ethnic/cultural background and environment of the students in Nakuru could be encouraging the drive to achieve which is transferred to Biology. It could also be related to the high socio-economic background of students from Nakuru compared to Siaya. A study by Guliz and Semra (2011) indicated that a strong correlation between self-efficacy and high socio-economic status.

On the question of "gender" related differences, there were no gender differences in the motivational beliefs and self-regulation strategies. The effect size was weak. The boys were more self-efficacious than girls and also had low test anxiety. On the other hand, the girls had a higher intrinsic value for Biology than the boys. The girls' scores on cognitive strategy and self-regulation were also higher than that of boys indicating a strong self-regulation strategy. These findings are also similar to the findings of Tang and Neber (2008) who found non-significant gender differences on certain motivational constructs and self-regulation strategies at the same time there were contradictory effects. Two studies in the recent past have shown non-significant gender differences in affective variables of attitude. Prokop, Tuncer and Chuda, 2007; Usak et al., 2009, found non-significant gender difference on affective variables of attitude. The absence of gender differences could also be attributed to affirmative action policies being aggressively implemented by the government of Kenya in the ministry of education.

Data analysis on the factor "grade" revealed that there existed some grade-related differences on some grade levels although the multivariate analysis indicated the effect size was low $\left(\eta^{2}=0.046\right)$. The findings did not provide any trend with regard to grade levels. However there were significant differences in pairs of classes in some domains. It is worth noting that no differences were in favor of grade 11 class for any of the constructs of the variables of the study. This could be due to the fact that this cohort of students had low motivational beliefs and self-regulation strategies. There were also no significant grade level differences with regard to self-efficacy and cognitive strategy. Where there were significant differences between grade 12 and any class it was in favor of the grade 12 students. It would appear that the grade 12 students had matured in the academic process and were focused on achieving their personal goals hence were more self-regulated than the rest of the classes. Again biology is an optional subject at grade 11 and 12 level in Kenya. The grade 12 students must have had strong intrinsic values for Biology hence their choice of the subject. The grade 12 students also had low test anxiety in biology compared to the other classes. This can be attributed to the fact that they have been exposed to a series of examinations through the four years that they had been in school and therefore have overcome some anxieties associated with biology examinations.

\section{Conclusion}

This study has revealed a number of differences in motivational beliefs and the strategy variables. In terms of self-efficacy, the Nakuru students seem to be more self-efficacious than their Siaya counterparts. There are significant differences in the other constructs under the study. There were no gender differences in any of the constructs under the study. There is need for a continuous affirmative action campaigns in education to attain equity especially in biology education. The study did not reveal any trend with regard to grade-level differences however there were grade level differences in some classes all in favor of the grade 12 class.

The present study was based on self-reported data. There is need for some studies that use multi-method approaches which do not merely rely on self-reported data. This study was also limited to the co-educational schools that usually exhibit moderate performance in examinations. Studies could be expanded to low and high achieving schools. There is also need to replicate studies in this area. 


\section{References}

Bandura, A. (1982). Self-Efficacy Mechanism in Human Agency. American Psychologist, 37, 122-147. http://dx.doi.org/10.1037/0003-066X.37.2.122

Bandura, A. (2001). Social Cognitive Theory: An Agentic Perspective. Annual Review Psychology, 52, 1-26. http://dx.doi.org/10.1146/annurev.psych.52.1.1

Basco, R. E., \& Olea, M. T. (2013). Correlation between Anxiety Level and Academic Performance of BS Biology Freshmen Students. International Journal of Educational Research and Technology, 4, 97-103.

Boekaerts, M. (2002). Motivation to Learn: Education Practices, Series 10. International Academy of Education. http://www.ibe.unesco.org

Cavas, P. (2011). Factors Affecting the Motivation of Turkish Primary Students for Science Learning. Science Education International, 22, 31-42.

Dancun, T. G., \& Mc Keachie, W. J. (2005). The Making of the Motivated Strategies for Learning Questionnaire. Educational Psychologist, 40, 117-128. http://dx.doi.org/10.1207/s15326985ep4002_6

Dornyei, Z. (2005). The Psychology of the Language Learner: Individual Differences in Second Language Acquisition. Mahwar, NJ: Lawrence Erlbaum.

Eccles, J. S., \& Wigfield, A. (2002). Motivational Beliefs, Values and Goals. Annual Review of Psychology, 53, $109-132$. http://dx.doi.org/10.1146/annurev.psych.53.100901.135153

Gall, M. D., Borg, W. R., \& Gall, J. P. (2003). Educational Research: An Introduction (7th ed.). New York: Longman, Inc.

Gaskill, P. J., \& Murphy, P. K. (2004). Effects of a Memory Strategy on Second Graders Performance and Self-Efficacy. Contemporary Educational Psychology, 29, 27-49. http://dx.doi.org/10.1016/S0361-476X(03)00008-0

Greene, B. A., \& Miller, R. B. (1996). Influences on Achievement: Goals, Perceived Ability, and Cognitive Engagement. Contemporary Educational Psychology, 21, 181-192. http://dx.doi.org/10.1006/ceps.1996.0015

Green, S. K. (2002). Using an Expectancy-Value Approach to Examine Teachers' Motivational Strategies. Teaching and Teacher Education, 18, 989-1005. http://dx.doi.org/10.1016/S0742-051X(02)00055-0

Guliz, K. \& Semra, S. (2011). Elementary Students' Self-Efficacy Beliefs in Science: Role of Grade Level, Gender and Socio-Economic Status. Science Education International, 22, 72-79.

Jahedi, S. (2007). A Study of Relationship between Motivational Beliefs and Self-Regulated Strategies and Academic Achievement of School Students. PhD Thesis, Pune: University of Pune.

Karatas, H., Alci, B., \& Aydin, H. (2013). Correlation among High School Senior Students Test Anxiety, Academic Performance and Points of University Entrance Exam. Educational Research Reviews, 8, 919-926.

Keraro, F. N., Okere, M. I. O., \& Anditi, Z. O. (2013). Cultural Influence on Pupils Understanding of Conception, Birth of Twins and Sex Determination in Kenya. International Education Studies, 6, 11-21. http://dx.doi.org/10.5539/ies.v6n5p11

Linnenbrink, E. A., \& Pintrich, P. R. (2002). Motivation as an Enabler for Academic Success. School Psychology Review, 31, 313-328.

Marcou, A., \& Philippou, G. (2005). Motivational Beliefs, Self-Regulated Learning and Mathematical Problem Solving. In H. L. Chick, \& J. L. Vincent (Eds.), Proceedings of the 29th Conference of the International Group for the Psychology of Mathematics Education (Vol. 3, pp. 297-304). Melbourne: PME.

Meece, J. L., Glienke, B. B., \& Burg, S. (2006). Gender and Motivation. Journal of School Psychology, 44, 351-373. http://dx.doi.org/10.1016/j.jsp.2006.04.004

Mezei, G. (2008). Motivation and Self-Regulated Learning: A Case Study of a Pre-Intermediate and an Upper-Intermediate Adult Student. WoPaLP, 2, 79-104.

Mih, V., \& Mih, C. (2010). Components of Self-Regulated Learning: Implications for School Performance. Acta Didactica Napocensia, 3, 39-48.

Mills, H. R. (1991). Teaching and Training: A Handbook for Instructors (3rd ed.). London: Macmillan.

Nelson, R. M., \& Debacker, T. K. (2000). Motivation to Learn Science: Differences Related to Gender, Class Type, and Ability. Journal of Educational Research, 93, 245-255. http://dx.doi.org/10.1080/00220670009598713

Nolen, B. S., \& Haladyna, T. M. (1990). Motivation and Studying in High School Science. Journal of Research in Science Teaching, 27, 115-126. http://dx.doi.org/10.1002/tea.3660270204

Ozkan, S. (2003). Roles of Motivational Beliefs and Learning Styles on 10th Grade Students' Biology Achievement. Msc Thesis, Ankara: Middle East Technical University.

Palmer, D. (2005). A Motivational View of Constructivist-Informed Teaching. International Journal of Science Education. 27, 1853-1881. http://dx.doi.org/10.1080/09500690500339654 
Pintrich, R. R., \& DeGroot, E. V. (1990). Motivational and Self-Regulated Learning Components of Classroom Academic Performance. Journal of Educational Psychology, 82, 33-40. http://dx.doi.org/10.1037/0022-0663.82.1.33

Pintrich, P. R., Marx, R. W., \& Boyle, R. A. (1993). Beyond Cold Conceptual Change: The Role of Motivational Beliefs and Classroom Contextual Factors in the Process of Conceptual Change. Review of Educational Research, 63, 169-199. http://dx.doi.org/10.3102/00346543063002167

Pintrich, P. R. (2003). A Motivational Science Perspective on the Role of Student Motivation in Learning and Teaching Contexts. Journal of Educational Psychology, 95, 667-686. http://dx.doi.org/10.1037/0022-0663.95.4.667

Prokop, P., Tuncer, G., \& Chuda, J. (2007). Slovakian Students’ Attitude toward Biology. Eurasia Journal of Mathematics, Science \& Technology Education, 3, 287-295.

Tabachnick, B. G., \& Fidell, L. S. (2007). Using Multivariate Statistics (5th ed.). Boston, MA: Allyn and Bacon.

Tang, M., \& Neber, H. (2008). Motivation and Self-Regulated Science Learning in High Achieving Students: Differences Related to Nation, Gender and Grade Level. High Ability Studies, 19, 103-116. http://dx.doi.org/10.1080/13598130802503959

Tuan, H. L., Chin, C. C., \& Shieh, S. H. (2005). The Development of a Questionnaire to Measure Students' Motivation towards Science Learning. International Journal of Science Education, 27, 634-659. http://dx.doi.org/10.1080/0950069042000323737

Usak, M., Prokop, P., Ozden, M., Ozel, M., Bilen, K., \& Erdogan, M. (2009). Turkish University Students’ Attitude toward Biology: The Effect of Gender and Enrolment in Biology Classes. Journal of Baltic Science Education, 8, 88-96.

Yucel, M. S. (2013). The Effect of Blog Use on Self-Regulatory Learning of Prospective German Language Teachers. Educational Research Reviews, 8, 226-233.

Zimmermann, B. J. (1989). A Social Cognitive View of Self-Regulated Learning. Journal of Educational Psychology, 81, 329-339. http://dx.doi.org/10.1037/0022-0663.81.3.329

Zimmerman, B. J. (1990). Self-Regulated Learning and Academic Achievement: An Overview. Educational Psychologist, 25, 3-17. http://dx.doi.org/10.1207/s15326985ep2501_2 